\title{
Sistema de Informações sobre Mortalidade em municípios de pequeno porte de Minas Gerais: concepções dos profissionais de saúde
}

\author{
Mortality Information System in small municipalities \\ of Minas Gerais state: concepts of health professionals
}

Deise Campos ${ }^{1}$

Salime Cristina Hadad ${ }^{2}$

Daisy Maria Xavier de Abreu ${ }^{3}$

Mariângela Leal Cherchiglia ${ }^{4}$

Elisabeth França ${ }^{4}$

\footnotetext{
${ }^{1}$ Gerência de Ensino e

Pesquisa, Fundação

Hospitalar do Estado de

Minas Gerais. Alameda

Vereador Álvaro Celso 100,

Centro. 30150-260 Belo

Horizonte MG.

deise_campos@hotmail.com

${ }^{2}$ Gerência de Tecnologia de

informação em Saúde,

Secretaria Municipal de

Saúde de Belo Horizonte.

${ }^{3}$ Grupo de Pesquisas em

Epidemiologia e Avaliação

em Saúde, Faculdade de

Medicina, Universidade

Federal de Minas Gerais.

${ }^{4}$ Programa de Pós-

Graduação em Saúde

Pública, Faculdade de

Medicina, Universidade

Federal de Minas Gerais.
}

\begin{abstract}
Strategies to accelerate the consolidation process of health information systems and make it possible to obtain reliable data on vital statistics are urgently needed. This qualitative study sought to understand the concepts of municipal administrators and Epidemiology managers about the Mortality Information System (MIS) in the Northeast region of Minas Gerais, one of the poorest in the state with the highest proportions of deaths with ill-defined causes. Professionals from ten municipalities were interviewed and their answers evaluated by content analysis. It was found that the MIS was perceived as important for management, but there was a general perception among respondents that it served the state and federal managers rather than the municipality in the planning of health actions. Improvements were reported in the physical structure of the municipalities to make the MIS operational, but also shortcomings related to lack of trained human resources for the systematic use and production of data at the local level and with high staff turnover. Partnerships between the health department with other state sectors can contribute to reduce under-registration of events and deaths with ill-defined causes.
\end{abstract}

Key words Qualitative analysis, Information systems, Mortality records, Health evaluation, Under-registration
Resumo Estratégias que acelerem o processo de consolidação dos sistemas de informações em saúde e permitam a obtenção de dados confiáveis a partir das estatísticas vitais são uma necessidade urgente. Neste estudo, de natureza qualitativa, buscou-se compreender as concepções de gestores municipais e gerentes de Epidemiologia acerca do Sistema de Informações sobre Mortalidade (SIM) na Macrorregião Nordeste de Minas Gerais, uma das mais pobres do Estado e com maiores proporções de óbitos por causas mal definidas. Foram entrevistados profissionais em dez municipios. Utilizou-se a técnica de análise de conteúdo. Verificouse que o SIM era reconhecido como importante para a gestão, mas havia uma percepção generalizada entre os entrevistados de que ele atendia mais aos gestores estadual e federal do que ao município no planejamento de ações de saúde. Foram relatadas melhorias quanto à estrutura física dos municípios para operacionalizar o SIM, mas também lacunas relacionadas com a carência de recursos humanos capacitados para o uso sistemático e produtivo dos dados no nível local e com a rotatividade de profissionais. Parcerias entre a secretaria de saúde e outros setores do Estado podem contribuir para a redução da subnotificação de eventos e dos óbitos com causa mal definida.

Palavras-chave Análise qualitativa, Sistemas de Informação, Registros de mortalidade, Avaliação em Saúde, Subregistro 


\section{Introdução}

O Sistema de Informação sobre Mortalidade (SIM) do Ministério da Saúde (MS) foi criado em 1975, com cobertura nacional, para subsidiar o planejamento e a análise da situação de saúde da população brasileira. O SIM é composto por um conjunto de ações que incluem desde a coleta e processamento de dados até a divulgação das informações sobre os óbitos registrados. As secretarias municipais de saúde (SMS) são gestoras do SIM no nível municipal e são responsáveis por estabelecer e divulgar diretrizes, normas técnicas, rotinas e procedimentos de gerenciamento do sistema em caráter complementar à atuação das esferas Federal e Estadual ${ }^{1}$.

O preenchimento da Declaração de Óbito (DO), distribuída pelo MS, instrumento único de coleta de dados, é de responsabilidade do médico que atestou o óbito. Na DO constam informações sobre causas do óbito e características demográficas, entre outras ${ }^{1}$. Os dados são inseridos no sistema computacional no município de ocorrência do óbito e seguem para as Secretarias de Estado de Saúde (SES), que consolidam os dados, realizam a retroalimentação para o município e transmitem o arquivo para a base de dados nacional no $\mathrm{MS}^{1,2}$. Os dados consolidados em nível federal possibilitam a divulgação das informações e a análise da situação de saúde da população para garantir a integralidade da atenção, individual ou coletiva, objetivo da Vigilância em Saúde².

Como outros países, o Brasil tem investido recursos na implantação e manutenção do sistema de informações sobre óbitos. É justamente por ser uma das principais fontes de dados em saúde que se torna imperioso conduzir estudos de avaliação do SIM. A avaliação está associada à necessidade e à possibilidade de intervir para mudar, com o objetivo de contribuir na tomada de decisão acerca de uma intervenção ou progra$\mathrm{ma}^{3,4}$. Estudos recentes têm demonstrado que, não obstante o longo tempo de sua implantação e as melhorias recentes, o SIM ainda enfrenta, especialmente nas regiões mais carentes de recursos, problemas na captação dos eventos ${ }^{5-7}$ e no processamento e análise da informação, devido em parte à precária capacitação de profissionais para gerenciar os sistemas de informação e à alta rotatividade de pessoal responsável pelos processos de trabalho ${ }^{8}$. Também têm sido ressaltadas dificuldades de gestão e na utilização dos sistemas de informações em saúde em pequenos municípios? ${ }^{9}$ Essas condições resultam em sub- notificação e baixa qualidade dos dados, como, por exemplo, elevada proporção de óbitos com causa mal definida ${ }^{10,11}$.

Em Minas Gerais, a cobertura dos óbitos foi estimada em $89,9 \%$ e a proporção de causas mal definidas de morte foi de $11,3 \%$, em $2008^{12,13}$. No entanto, observa-se uma heterogeneidade da qualidade da informação sobre óbitos entre as regiões do estado. Em particular, a macrorregião Nordeste tem apresentado piores resultados quanto a esses indicadores e se caracteriza pelo baixo nível socioeconômico, reduzido número de médicos e de leitos hospitalares por habitante ${ }^{13-}$ ${ }^{15}$. Em estudo que investigou as informações sobre nascimentos e óbitos coletados rotineiramente em Minas Gerais, observou-se que essa macrorregião apresentou maior proporção de microrregiões e municípios considerados "não adequados" do ponto de vista da cobertura e da qualidade dos dados ${ }^{16}$.

Essa visível diferenciação de resultados entre as regiões provocou o interesse em entender como questões relativas aos processos de trabalho e à estrutura que os sustenta interferem na qualidade da informação. Para isso, a observação dos processos onde eles acontecem pode se configurar em uma estratégia de pesquisa adequada. Assim, este trabalho teve como objetivo apresentar e discutir a concepção dos gestores municipais e gerentes de Epidemiologia sobre os processos de notificação de óbitos e da estrutura do SIM em municípios da macrorregião Nordeste de Minas Gerais.

\section{Procedimentos metodológicos}

Trata-se de uma pesquisa avaliativa, de natureza qualitativa, que abordou algumas questões sobre o SIM em municípios de Minas Gerais. Este estudo é parte do projeto de pesquisa Avaliação do Sistema de Informações sobre Mortalidade na Macrorregião Nordeste de Minas Gerais que teve por objetivo avaliar o SIM, investigar a subnotificação de óbitos e esclarecer causas de morte com o método da autópsia verbal ${ }^{7,15}$.

A população da Macrorregião Nordeste foi estimada em 881.340, em 2007. A Secretaria de Estado de Saúde de Minas Gerais está organizada em 28 Gerências Regionais de Saúde (GRS) e os fluxos operacionais do SIM acontecem entre as GRS e os municípios do seu território ${ }^{13}$. A Macrorregião Nordeste se constituía de 63 municípios, em 2007, sendo que a maioria possuía menos de 20 mil habitantes (81\%) e apenas dois 
deles possuíam mais que 40 mil habitantes. No período foram registrados 4.878 óbitos no SIM dos quais 23\% foram classificados no Capítulo XVIII da CID- $10^{13}$, isto é, com causa mal definida de morte. A proporção de óbitos com causa mal definida foi variável entre os municípios selecionados para este estudo (0,0 a 44,4\%). Três municípios possuíam hospitais e Comitês de investigação de óbitos atuantes; três possuíam hospitais, mas não Comitê; e um deles possuía Comitê, mas nenhum hospital.

A coleta de dados foi realizada entre abril e julho de 2008, em dez municípios das GRS de Diamantina (Virgem da Lapa), Pedra Azul (Águas Vermelhas, Comercinho, Felisburgo, Itaobim, Jequitinhonha) e Teófilo Otoni (Campanário, Frei Gaspar, Machacalis, Serra dos Aimorés) ${ }^{15}$.

Foram entrevistados gestores municipais e gerentes de Epidemiologia, que são os atores diretamente envolvidos no processo de produção e utilização dos dados de mortalidade. Para compreender as suas concepções sobre o SIM, nas entrevistas foram abordadas questões relacionadas à estrutura do serviço (recursos humanos e materiais), processos (fluxos e adequação às normas técnicas) e resultados (subnotificação e proporção de óbitos com causa mal definida). O roteiro da entrevista foi elaborado com questões abertas de modo a permitir uma reflexão sobre as atividades desenvolvidas, com um aprofundamento crescente em direção ao SIM propriamente dito. As entrevistas foram realizadas em local e hora previamente escolhidos pelos entrevistados e duraram de uma a duas horas. As respostas foram gravadas e transcritas e optou-se pela identificação das falas com a letra " $G$ ” para gestores municipais e a letra "E" para os gerentes dos Serviços de Epidemiologia.

Utilizou-se a técnica da análise de conteúdo, que considera que todos os elementos do corpus tem significado e todo material deve ser analisado e incorporado à análise. Isso se justifica quando o interesse é compreender o significado dos fenômenos relativos aos processos de trabalho para melhorar a qualidade do sistema e entender mais profundamente o comportamento dos atores envolvidos no processo ${ }^{17-19}$. A análise de conteúdo pelo processo de impregnação consistiu em ler e reler inúmeras vezes os textos buscando identificar temas emergentes, categorias e subcategorias comuns. Em seguida, os textos foram analisados como um único bloco, o que permitiu realizar ajustes na lista de categorias, com inclusão ou exclusão de categorias e subcategorias. A codificação dos dados foi realizada de forma independente pelos membros do grupo de pesquisa. Para análise dos dados qualitativos utilizou-se o programa Weft QDA versão 1.0.1 (University of Surrey, Reino Unido), indexando cada trecho referente a uma ou mais categorias de conteúdo com seus códigos correspondentes, possibilitando a seleção de uma determinada categoria e os trechos de discurso correspondentes. Essas categorias foram agrupadas em quatro temas que serão desenvolvidos a seguir.

O projeto foi aprovado pelo Comitê de Ética em Pesquisa da Universidade Federal de Minas Gerais. Foram cumpridos todos os princípios éticos que regem as pesquisas envolvendo seres humanos.

\section{Análise dos resultados e discussão}

\section{A utilidade da informação em saúde para os gestores municipais}

Em um primeiro momento, os gestores consideraram a informação em saúde como muito importante para a identificação de prioridades em saúde pública. Os sistemas de informação foram apontados por alguns entrevistados como suporte para as estratégias municipais de identificação de problemas prioritários de saúde por meio da análise de dados e comparação dos resultados obtidos nos indicadores e metas pactuadas com o governo do Estado:

Nós sempre avaliamos os indicadores, nós temos as pactuações, que a gente faz agora o SIMPACTO. Sentamos com o corpo de enfermagem e vamos avaliar cobertura, o que a gente tem que atingir e porque a gente não tá atingindo [...]. (G4)

As falas dos gestores sobre os usos dos sistemas de informação indicam uma postura mais política e elaborada sobre a questão:

[...] [os sistemas de informações são úteis no] monitoramento e na avaliação, seria uma forma do Estado, a nível estadual ou nacional, ter um conhecimento por regional, por município. (G1)

[...] o papel fundamental do Sistema é organização da rede em si e financeiramente você ter suporte, ter capacitação direcionada para os profissionais e planejamento das ações [...] nas diversas regiões, que cada região apresenta sua característica. Então eu acho que é fundamental que o governo tenha à mão esses dados pra poder estar fazendo o gerenciamento dessas atividades e um desenho das politicas de saúde. (G3)

A informação local, seja ela formal (dados coletados) ou informal (informante chave), ser- 
viria para adequar o rumo das atividades desenvolvidas no município. Por outro lado, agregar a informação por uma área geográfica maior, possibilitaria uma melhor definição de políticas públicas e ações mais abrangentes. De toda forma, na visão dos entrevistados, os dados seriam mais úteis para os níveis estadual e federal do que para o municipal.

Em relação ao SIM, como será discutido adiante, observou-se que o foco das SMS estava na provisão da assistência médica aos munícipes não sendo esse sistema de informação diretamente conectado à missão assistencial da SMS. O uso do SIM foi identificado como limitado à leitura das informações que chegavam da GRS e à tarefa de pactuar os indicadores com o Estado - uma função momentânea, uma vez que o poder local atua a partir de contatos pessoais, como já apontado por Cohn et al. ${ }^{20}$. O uso da informação sobre mortalidade para direcionamento de políticas públicas não foi considerado como motivo suficiente para que o município se preocupasse com o SIM: a SMS simplesmente aderia e executava o que fosse normatizado e financiado ${ }^{20}$. Como os relatórios da GRS eram anuais e não se realizava a consulta à retroalimentação dos dados fornecidos pelo sistema, parece haver uma dissociação entre o que os entrevistados disseram saber sobre o SIM e a forma como se posicionavam em relação à inserção do sistema no cotidiano da SMS. E provavelmente por não utilizarem os dados ou por dominarem apenas os dados mais simples, os municípios não se consideravam responsáveis pela gerência do sistema no seu território.

\section{Como são obtidas as informações em saúde para a gestão municipal}

Em um segundo momento, os entrevistados relataram que o agente comunitário de saúde (ACS) representava a fonte de informação mais estratégica, pois assumia o papel de educador e elo de comunicação com a comunidade:

Os agentes comunitários, na minha visão, são a base da saúde, tudo gira em torno deles. Não só da saúde, como da educação, da rede social, porque a gente trabalha integrado. [...] Porque eles vão estar entrando na casa e vão estar repassando pra gente né aquilo ali pra poder trabalhar com mais eficácia. (G6)

Porém, aparentemente, o ACS não tinha vínculo com o serviço de epidemiologia e nem estava preparado o suficiente para trabalhar com a informação que coletava:
[...] Eu acho que o principal é o agente de saúde que tá buscando... infelizmente quando a gente pega a gente pega os agentes todos não têm a mesma preparação... o conhecimento dos gestores de saúde pra poder tá trazendo essas informações... muitas vezes ela se perde porque não chega a informação de qualidade né... (G4)

Assim também, problemas de saúde eram identificados nas reuniões das equipes de saúde:

[...] as equipes de PSF porque aí cada equipe vai tá trabalhando na sua área de abrangência, uma área menor, e ali vai tá conhecendo os problemas e a realidade da comunidade [...]. (G9)

Apesar de somente quatro municípios possuírem um Comitê de prevenção de óbitos infantis e maternos atuante, sua criação foi citada pelos gestores municipais de saúde como instrumento para melhoria da qualidade dos dados sobre mortalidade e para sensibilização do profissional médico, apesar das dificuldades relatadas para sintetizar os resultados e divulgá-los:

Os Comitês de Mortalidade Infantil e Materno. Já estamos com eles em ação, porém a avaliação trimestral a gente percebe que isso só foi possível pelo próprio programa Viva Vida que nos orientou e capacitou equipe nesse sentido é... apesar de alguns momentos a gente ainda não conseguir estabelecer uma sistemática de relatório. (G4)

Semelhantemente, os diversos eventos municipais foram citados como sendo espaços para ações educativas e apreensão da realidade em saúde por meio do contato com os munícipes. Parcerias intersetoriais também proveriam informações sobre a saúde da população como a Secretaria de Educação, os Conselhos Municipais de Saúde além dos dados do Programa Bolsa Família:

[...] Então a gente convida a comunidade pra participar da reunião do Conselho Municipal de Saúde e lá a gente registra várias solicitações e informações pros moradores. Então ali a gente adota a política de ação da saúde dentro da realidade. (G4)

As fontes informais de informação sobre mortalidade, que podem ser consideradas mais inusitadas, são as idas a velórios e anúncios de velório por carros de som nas ruas:

[...] Já orientei os meninos que toda vez que tem... alguns óbitos que tá tendo eu tô indo atrás... tem lá eu vou... tô nem aí eu vou lá no velório... entendeu... chego lá... além do que sempre tem alguém que passa mal, alguma coisa... então eu sempre tô buscando isso... tá por perto, tá por dentro, sair, o que foi feito lá, qualquer coisa, entendeu? Pra poder ter esse acompanhamento sim... (E1)

Essa maneira informal de obter informação sobre a saúde no município, isto é, por meio de 
informantes-chave, parecia satisfazer ao gestor e ser suficiente para a tomada de decisões no nível municipal. Por sua vez, os gerentes dos serviços de Epidemiologia consideravam o SIM municipal relativamente adequado, refletindo ao menos parcialmente a realidade local. Ou seja, na fala dos entrevistados transparece o entendimento de que, nos pequenos municípios, como os profissionais conhecem todo mundo, não é necessário se preocupar com a coleta de dados estatísticos. Pode estar embutida aí uma explicação para a subnotificação no SIM. Nesse sentido, os profissionais da assistência à saúde podem ter um papel decisivo na redução da subnotificação como já foi verificado com relação às doenças de notificação compulsória ${ }^{21}$.

\section{Dificuldades e avanços \\ na operacionalização do Sistema de Informações sobre Mortalidade (SIM) nos municípios}

Uma das dificuldades identificada pelos gestores nos municípios de pequeno porte foi a reduzida disponibilidade de profissionais capacitados para a realização de análises dos dados do SIM e a falta de recursos que propiciassem sua fixação no município.

[...] a gente não tem aqui um departamento de epidemiologia pra gente tá analisando melhor, fazendo um diagnóstico mesmo da situação de saúde do município porque é o que tá precisando da gente tá fazendo agora. (G10)

Desse modo, a rotatividade de pessoal teria impedido avanços na consolidação do sistema de informação:

Toda categoria nós sabemos que tem alguém mais preparado e tem alguém que está chegando, eu não chamaria de mal-preparado, mas não tinha a experiência que talvez a gente necessitava. E as pessoas que estavam mais capacitadas e que tinham uma experiência maior iam para os grandes centros e conosco ficavam aqueles assim... que veio, mas que tava com dificuldade parecida com a nossa. A resolutividade de problemas não avançava [...]. (G2)

Neste contexto, os gerentes de epidemiologia ressaltaram que não havia um profissional que analisasse os dados:

[...] a análise desses dados o que a gente realmente não faz.[...] nem sempre você tem as pessoas, você tem que começar do nada pra tá procurando se informar [...] E a questão da epidemiologia eu acho que ela ainda peca nos nossos pequenos municípios, ela deixa muito a desejar a questão de análise de dados, [...] a questão de você não poder dispor de uma equipe só pra análise de dados né, tem muito isso aí, questão né do recurso. (E4)

Alguns profissionais responsáveis pela Epidemiologia declararam que não conheciam o trabalho a ser realizado ao assumirem o cargo e apontaram a importância das capacitações:

Porque falta capacitação mesmo do profissional a respeito do que deve ser feito. Eu acho que é voltado muito [...] pra atenção primária, a doença, patologia. [...] essa parte das investigações dos óbitos realmente não é levado muito a sério [...], mas como eu tinha te falado não foi nem passado pra mim essa. [...]. Essa preocupação com os óbitos que vem a ser, você [a entrevistadora] despertou um interesse muito bom. (E2)

Como eles, os gestores também manifestaram o desejo de serem capacitados no uso das informações em saúde e dos sistemas de informação.

A problemática da capacitação e da rotatividade dos recursos humanos fica mais clara quando se trata do conhecimento acerca da gestão do sistema e da utilização da informação como instrumento de gestão no dia a dia das SMS, como observado em outros estudos ${ }^{8,22}$.

Cabe ressaltar que em seis dos dez municípios visitados, as atividades de vigilância em saúde eram executadas de forma fragmentada por diferentes profissionais de diversos setores da SMS, isto é, não foi identificado um responsável pela epidemiologia. Esse fato por si já indica a dificuldade dos pequenos municípios de contarem com recursos humanos qualificados, mesmo para a execução de atividades fundamentais.

Contudo, segundo os entrevistados, além da capacitação dos profissionais, o desenvolvimento do serviço estaria relacionado com a disponibilidade de estrutura adequada para o trabalho. Foram citadas como melhorias recentes a aquisição de mobiliário, biblioteca e carro próprio dentro de um contexto de adequação de toda a rede municipal de saúde.

Ano passado isso aqui tava um caos. Aí chegou armário, chegou livros [...] carros novos [...] pra poder sair se tiver que fazer busca ativa. (E1)

Uma situação relevante relatada por mais de um entrevistado foi a descontinuidade da informação pelo desaparecimento físico e digital de documentos processados em gestões municipais anteriores

[...] a questão da rotatividade de funcionáriose até de documentos que você acaba por não conhecer. Parece que quando as pessoas saem, eu não sei o que elas fazem com a documentação. (E4)

Quanto ao apoio do Estado, os entrevistados apontaram como avanço as análises continuadas 
de alguns indicadores municipais pela GRS ao mesmo tempo em que observaram uma melhoria na comunicação entre as esferas governamentais. Para os gerentes de epidemiologia, a GRS também acompanhava o município apontando os problemas a serem enfrentados na coleta de dados:

Esses dias tive reunião com a GRS e ela chegou e passou pra mim os dados tudinho do ano passado. O que eu tinha que melhorar, o que tava bom e o que tinha que melhorar. (E1)

Entretanto, foi ressaltada a importância de se trabalhar com dados mais recentes:

A gente chega em 2008 e trabalha com o de 2006. Se você tá em 2007, você trabalha com o de $2005[\ldots]$ (G1)

Apesar dos dados sobre mortalidade serem gerados no município, os gestores manifestaram o desejo de terem informações oportunas. Provavelmente isso se devia ao desconhecimento sobre a retroalimentação de dados em tempo real no SIM. Ou seja, os municípios não precisariam depender dos relatórios anuais das GRS para obter a listagem dos óbitos de seus munícipes.

Outra possível explicação para as dificuldades enfrentadas pelos municípios relativas à análise de dados epidemiológicos seria que a informatização da vigilância epidemiológica poderia ser considerada um fato relativamente novo, sendo recente a estruturação desse serviço em alguns municípios:

[...] é importante informatizar. Eu acho que começou a informatizar aqui em 2005... 2005 ou 2004 se não me engano. (G8)

A introdução de sistemas de informação informatizados colaborou para sua reorganização, ocorrida principalmente mediante cobrança por parte da SES, com a possibilidade de perda de recursos financeiros pelo município.

Mesmo não utilizando os dados do sistema no cotidiano da gestão, alguns gestores consideraram que o município que não assumia a digitação dos dados da DO não dominava o SIM:

O SIM é essa deficiência [...] porque municípios do nosso porte não têm nenhum domínio sobre o SIM na verdade. Aqui não é digitado. Tenho conhecimento do relatório do óbito dos meus municipes. Então assim, talvez se a informação tivesse ali mensal. (G9)

Foram também relatados problemas de instalação dos programas para digitação dos dados nos sistemas e falta de disponibilidade de acesso a internet.

A respeito dos programas, eu não tenho disponibilidade de internet para pesquisas né pra acompanhar a situação do município, essas coisas. (E2)
No entanto, a GRS prestava apoio oportuno para os problemas com os computadores e os sistemas.

Qualquer hora lá eles estão disponíveis pra gente sim. (E1)

Em síntese, a pequena disponibilidade e a rotatividade de profissionais capacitados para operacionalização do sistema de informações provavelmente contribuíram para a pouca utilização dos dados e consequentemente para a menor valorização da gestão do sistema pelo município. Por outro lado, as melhorias relatadas em termos de infraestrutura e suporte técnico podem apontar o melhor relacionamento do município com a GRS e sugerem mudanças nessa gestão.

\section{Os possíveis caminhos da subnotificação do óbito e da ocorrência do óbito com causa mal definida no SIM}

A proporção de óbitos com causas mal definidas e a subnotificação de óbitos são indicadores da qualidade do sistema de saúde, no que se refere ao acesso e qualidade da assistência pres$\operatorname{tada}^{23}$. Espera-se que esses indicadores não ultrapassem o valor de 7 a $10 \%$ do total de óbi$\operatorname{tos}^{24,25}$. Porém, a Macrorregião Nordeste de Minas Gerais apresenta valores mais elevados que esses, como exposto anteriormente.

Ao serem questionados sobre o porquê da ocorrência de subnotificação de óbitos e de óbitos declarados com causa mal definida, os entrevistados relataram: sepultamento sem exigência de documento nos denominados cemitérios não oficiais, registro do óbito em cartório com emissão de DO como óbito sem assistência médica e dificuldade de controle da ocorrência dos eventos devido à grande extensão da zona rural.

Interessante notar que alguns entrevistados negaram haver sepultamento sem documentação no seu município enquanto outros confirmaram sua ocorrência:

[...] aqui nesse [cemitério] municipal só enterra se tiver a Declaração de Óbito ou então a Certidão. [...] Até os coveiros, vamos dizer assim, já tá sabendo o quanto esse serviço é importante [...] principalmente pro Ministério da Saúde saber quanto óbito. (E2)

[...] o cemitério daqui ele enterra as pessoas sem apresentarem a Declaração de Óbito. Olha eu, até por essa parte ser [do Departamento de] Obras, eu tinha falado com o responsável que precisa ser registrado dentro do cemitério, essa situação dos óbitos. (G2) 
A não cobrança da Certidão de Óbito para enterrar nesses cemitérios não oficiais pode ser um fator que explique a subnotificação do óbito no SIM, pela não emissão da DO pelo cartório:

Talvez uma não cobrança na hora de você enterrar [...]. E como é que eu vou digitar uma coisa que não existe? (E4)

Os motivos relatados para a ocorrência dos cemitérios não oficiais referem-se a questões culturais ou financeiras, pois o sepultamento mais próximo de casa e sem documentação não onera a família.

[...] o que minha mão alcança: o cemitério clandestino tá ali, eu não vou ter trabalho nenhum, não vou ter tanta despesa, não vou ter nada entendeu? [...] foi onde meu tio, meu avô, não sei quem foi enterrado, também quero ser enterrado aqui, mais fácil. (E1)

Neste ponto, cumpre-se dizer que apenas um cemitério visitado durante o trabalho de campo, localizado na sede de um dos municípios, exigia a Certidão de Óbito para o sepultamento e tinha registro das covas em livro próprio na prefeitura. Evidencia-se assim o desconhecimento por parte da SMS do que ocorre no município quanto aos sepultamentos, isto é, não há um controle dos eventos nem seu registro parece ser importante.

Segundo os relatos, a população prefere registrar o óbito em cartório (com emissão de DO como óbito sem assistência médica), devido à falta do profissional médico na cidade para atestar o óbito ou devido às dificuldades para envio do corpo ao IML, localizado em outro município:

Especificamente aqui acontece devido a falta de um médico aqui, residente aqui, que aqui não tem. Se acontecer um óbito depois de cinco horas da tarde não tem, quer dizer o cartório que é a solução. [...] se um cartório não tiver aberto aí leva lá no IML. Mas se tiver... ah não, no IML vai demorar mais, aí tem aquela burocracia. Então, eles já vão direto no cartório. Chega lá registra coloca lá como sem assistência médica, e pronto faz uma declaração e aí? E por que a pessoa morreu? (E3).

Para os gestores, o elevado número de óbitos registrados com causa mal definida ocorreria por dificuldades no estabelecimento de diagnóstico devido à falta de profissional médico ou de exames diagnósticos acessíveis à população:

[...] infelizmente o SUS local aqui não pode tá saindo pagando exame particular pra todo mundo né porque não tem recurso financeiro pra isso. Então a região ainda sofre muito com esses vazios assistenciais, não tem exames né e profissionais pra tá realizando os exames também. (G9)
Por outro lado, a adequação da estrutura física, a expansão da cobertura do PSF e a presença do ACS poderiam ter contribuído com a melhoria no acesso da população aos serviços com consequente esclarecimento das patologias mais prevalentes.

Outra justificativa levantada foi quanto aos pacientes encaminhados para tratamento fora de domicílio. Em caso de óbito, o médico do hospital não preenche a DO com causa definida porque não se verifica continuidade na assistência prestada:

Você não tem hospital na localidade, o que acontece? Manda pra hospital referência. Às vezes a referência não manda o laudo. Entendeu? Não é ele que acompanha o paciente, então tem essa dificuldade. (E1)

Reconhecendo falhas no preenchimento dos campos da DO, os gestores apontaram que tal fato poderia trazer prejuízo para os familiares do falecido e para o município: os familiares necessitam dos dados para efeito de pensão ou herança e o município necessita do dado correto para direcionar as ações de saúde.

... vamos pôr o caso assim, da DO, qual que éa importância da aposentadoria. Não é só... seria importante ela tá ali no dia-a-dia exigindo que o médico preencha a DO dele direitinho e tal. (G3)

Mas, os entrevistados consideraram que o não preenchimento correto da $\mathrm{DO}$ deveria ser cobrado do médico, responsável legal pelo documento. A falta de conhecimento sobre saúde pública por parte do profissional médico interferiria na qualidade do preenchimento da DO: Tem DO aqui com o nome da pessoa e a assinatura. O profissional não tem noção nenhuma de saúde pública porque tá gerando informação para ele mesmo. (G5).

$\mathrm{Na}$ visão de um dos gerentes de Epidemiologia, ocorreriam mais óbitos de pessoas jovens com causa mal definida do que em idosos e crianças devido ao fato daquela faixa etária ser naturalmente mais saudável e não passar por atendimento nos serviços de saúde.

Como de fato o jovem hoje ele só procura o hospital ou alguma coisa só em último caso. Quem procura mesmo aqui principalmente é, se não for criança, é o idoso. Então, quer dizer, nós vamos ter uma informação bem melhor do idoso, que éo caso que acontece aqui [...] a gente tem como estudar, mas não se faz um estudo pra saber de fato o que é. Não vai pra declaração de óbito que é feita no cartório (E3).

Isto é, como em geral não se realizava a investigação dos óbitos, mesmo a informação so- 
bre a causa da morte do idoso se perdia, pois o óbito era registrado diretamente no cartório.

Apesar de algumas facilidades disponibilizadas (cemitério municipal sem ônus para o munícipe e facilidade de transporte do corpo), a única ação específica relatada para reduzir a ocorrência de sepultamentos sem documentação foi a orientação de coveiros acompanhada da explicação de que o documento é importante para o Ministério da Saúde. Outras ações anteriormente relatadas (ida a velório, implantação de Comitê, orientação aos ACS, contratação de médico e expansão do PACS e PSF), não parecem ter relação com a intenção de melhorar o SIM e eram consideradas pelos entrevistados apenas como uma maneira de se conseguir dados para consumo imediato da gestão municipal. O SIM não era lembrado nas falas quando o assunto era a assistência à saúde, isto é, aparentemente não fazia parte da "área da saúde". Por outro lado, a ampliação da cobertura do PSF e a criação de mais três IML na macrorregião, em 2007, devem ter contribuído para uma redução dos óbitos com causa mal definida nos últimos anos: esse indicador passou de $14,2 \% \mathrm{em}$ 2000 para $11,3 \%$ em $2008^{13}$.

A subnotificação de óbitos e a necessidade de aprimorar o processo de coleta de DO nos cartórios e estabelecimentos de saúde, assim como resgatar informações em outras fontes, inclusive em cemitérios não oficiais e com as parteiras tradicionais, são temas abordados em vários trabalhos no país ${ }^{5,8}$. Chama atenção neste estudo o fato de os relatos analisados indicarem que há problemas no entendimento por parte dos profissionais de que a SMS é a responsável pela gestão do SIM municipal e que essa responsabilidade envolve aprimorar os processos de busca ativa e investigação dos óbitos ${ }^{1,2}$.

\section{Considerações finais}

A importância do SIM e da informação sobre mortalidade é reconhecida nos pequenos municípios da Macrorregião Nordeste de Minas Gerais, porém parece ser uma percepção generalizada entre os gestores municipais de que o SIM atende mais aos gestores estadual e federal do que ao próprio município no planejamento de ações de saúde. No entendimento dos entrevistados, a falta de capacitação e a alta rotatividade dos profissionais que lidam com o SIM prejudicam a utilização do sistema como fonte de informação para a gestão da saúde do município.
Verificou-se que, apesar dos responsáveis pelo SIM conhecerem o que é preconizado pelo Ministério da Saúde quanto aos fluxos das DO, a rotina de coleta das informações segue um fluxo próprio que se cristalizou com o tempo. Ou seja, a dificuldade crônica de acesso e fixação do profissional médico parece ter imposto a emissão de DO pelos cartórios como regra. As atividades de busca ativa de óbitos e de investigação de óbitos com causa mal definida também parecem ainda não terem sido incorporadas às ações da vigilância em saúde.

Deve-se destacar que a ocorrência de reduzido número de óbitos em municípios de menor porte e sua dispersão entre as causas de morte dificultam a análise epidemiológica. Além disso, somente seis municípios tinham hospitais e, em geral, sabe-se que o sistema assistencial municipal se baseia predominantemente ou exclusivamente na atenção básica. Desta forma, o padrão de mortalidade captado no município pode não ser suficiente para expressar a carga de doença e auxiliar na tomada de decisões.

Assim, muitas vezes, é mais adequada a sistematização e a análise dos dados no nível regional. Nesse aspecto, o papel do Estado enquanto coordenador de áreas estratégicas da organização do sistema de saúde deve ser reforçado e, dentre elas, o monitoramento do processo de geração de informação deve estar presente no conjunto de atribuições da vigilância em saúde. Em muitas situações, torna-se necessário que a secretaria estadual de saúde e suas diretorias regionais assumam efetivamente a coordenação dos sistemas de informação. E nesse contexto, a utilização da informação municipal para tomada de decisões no nível regional pode trazer significado quando da execução das tarefas de coletar e processar os dados e pode estimular investimentos na melhoria da cobertura e da qualidade dos dados.

Ainda que esse estudo tenha se restringido à macrorregião Nordeste de Minas Gerais, provavelmente os achados e as considerações apontadas expressam a realidade de muitos municípios brasileiros quanto às dificuldades estruturais $\mathrm{e}$ fragilidades do SIM, que resultam em subnotificação de eventos e elevada proporção de óbitos por causa mal definida.

Sabe-se que o SIM é um sistema complexo e que para ser operacionalizado requer que os diferentes profissionais envolvidos desempenhem suas funções de maneira efetiva. Portanto, os ACS e demais profissionais das ESF deveriam incorporar na sua rotina a busca e a notificação de óbitos, contribuindo para a redução da subnoti- 


\section{Colaboradores}

D Campos e E França participaram da concepção e delineamento do estudo, elaboração dos formulários, levantamento bibliográfico, análise dos dados e redação final do artigo. SC Hadad participou da análise dos dados, no levantamento bibliográfico, na discussão e na redação final do artigo. DMX Abreu e ML Cherchiglia participaram da concepção do estudo, elaboração dos formulários, análise dos dados e revisão crítica do artigo.

\section{Agradecimentos}

Aos colegas do Grupo de Pesquisas em Epidemiologia e Avaliação em Saúde, à Salete Diniz e Sueli Alvim da Secretaria de Estado de Saúde e à Priscila Kellen e Elieth Pedrosa pelo companheirismo e contribuição no campo. Aos acadêmicos Annelisa Lages, Lorena Machado e Pedro Trocoli. Às Secretarias Municipais de Saúde e às instituições que viabilizaram o projeto. Financiada pela Fapemig. Deise Campos foi bolsista CAPES e Fapemig.

\section{Referências}

1. Brasil. Ministério da Saúde (MS). Portaria MS/GM $n^{\circ} 116$, de 11 de fevereiro de 2009. Regulamenta a coleta de dados, fluxo e periodicidade de envio das informações sobre óbitos e nascidos vivos para os Sistemas de Informações em Saúde sob gestão da Secretaria de Vigilância em Saúde. Diário Oficial da União 2009; 12 fev.

2. Brasil. Ministério da Saúde (MS). Portaria MS/GM no 3.252, de 22 de dezembro de 2009. Aprova as diretrizes para execução e financiamento das ações de Vigilância em Saúde pela União, Estados, Distrito Federal e Municípios e dá outras providências. Diário Oficial da União 2009; 23 dez.

3. Silva LMV, Formigli VLA. Avaliação em saúde: limites e perspectivas. Cad Saude Publica 1994; 10(1): 80-91.

4. Contandriopoulos AP, Champagne F, Denis JL, Pineault R. A avaliação na área da saúde: Conceitos e métodos. In: Hartz ZMA, organizador. Avaliação em saúde: dos modelos conceituais à prática na análise da implantação de programas. Rio de Janeiro: Fiocruz; 2000. p. 29-47.

5. Façanha MC, Pinheiro CP, Fauth S, Lima AWDBC, Silva VLP, Justino MWS, Costa EM. Busca ativa de óbitos em cemitérios da Região Metropolitana de Fortaleza, 1999 a 2000. Epidemiologia e Serviços de Saúde 2003; 12(2):131-136.

6. Jorge MHPM, Laurenti R, Gotlieb SLD. Análise da qualidade das estatísticas vitais brasileiras: a experiência de implantação do SIM e do SINASC. Cien Saude Colet 2007; 12(3):643-654.

7. Cunha CC, Campos D, França EB. Uso da busca ativa de óbitos na avaliação do Sistema de Informações sobre Mortalidade em Minas Gerais, Brasil. Epidemiol. Serv. Saúde 2011; 20(3):275-286. 
8. Frias PG, Pereira PMH, Andrade CLT, Szwarcwald CL. Sistema de Informações sobre Mortalidade: estudo de caso em municípios com precariedade dos dados. Cad Saude Publica 2008; 24(10):2257-2266.

9. Vidor AC, Fisher PD, Bordin R. Utilização dos sistemas de informação em saúde em municípios gaúchos de pequeno porte. Rev Saude Publica 2011; 45(1):24-30.

10. Szwarcwald CL, Leal MC, Andrade CLT, Souza Júnior PRB. Estimação da mortalidade infantil no Brasil: o que dizem as informações sobre óbitos e nascimentos do Ministério da Saúde. Cad Saude Publica 2002; 18(6):1725-1736.

11. França E, Abreu DMX, Rao C, Lopez AD. Evaluation of causa-of-death statistics for Brazil, 2002-2004. Int J Epidemiol 2008; 37(4):891-901.

12. Brasil. Ministério da Saúde (MS). Secretaria de Vigilância em Saúde. Departamento de Análise da Situação de Saúde. Saúde Brasil 2010: uma análise da situação de saúde e de evidências selecionadas de impacto de ações de vigilância em saúde. Brasília: MS; 2011.

13. Brasil. Ministério da Saúde (MS). Secretaria de Vigilância em Saúde. Informações em Saúde. [acessado 2013 mar 29]. Disponível em: http://www2. datasus.gov.br/DATASUS/index.php

14. Lima EEC, Queiroz BL. A evolução do sub-registro de mortes e causas de óbitos mal definidas em Minas Gerais: diferenciais regionais. R. bras. Est. Pop. 2011; 28(2):303-320

15. Campos D, França EB, Loschi RH, Souza MFM. Uso da autópsia verbal na investigação de óbitos com causa mal definida em Minas Gerais, Brasil Cad Saude Publica 2010; 26(6):1221-1233.

16. França E, Abreu D, Campos D, Rausch MC. Avaliação da qualidade da informação sobre mortalidade infantil em Minas Gerais, em 2000-2002: utilização de uma metodologia simplificada. Rev Méd Minas Gerais 2006; 16(Supl.):S28-35.

17. Turano ER. Métodos qualitativos e quantitativos na área da saúde: definições, diferenças e seus objetos de pesquisa. Rev Saude Publica 2005; 39(3):507-514.
18. Bauer MW, Gaskell G. Pesquisa qualitativa com texto, imagem e som: um manual prático. Petrópolis: Vozes; 2006.

19. Bosi MLM, Mercado FJ. Avaliação qualitativa de programas de saúde: enfoques emergentes. Petrópolis: Vozes; 2006.

20. Cohn A, Westphal MF, Elias PE. Informação e decisão política em saúde. Rev Saude Publica 2005; 39(1): 114-121.

21. Barbosa MCL, Costa MCN, Teixeira MG, Mota ELA, Pereira SM. Efeitos da descentralização das ações de vigilância epidemiológica para as Equipes de Saúde da Família. Epidemiol. Serv. Saúde 2010; 19(4): 347-354.

22. Freitas FP, Pinto IC. Percepção da equipe de saúde da família sobre a utilização do sistema de informação da atenção básica - SIAB. Rev Latino-am Enfermagem 2005; 13(4):547-554.

23. Faúndes A, Parpinelli MA, Cecatti JG. Mortalidade de mulheres em idade fértil em Campinas, São Paulo (1985-1994). Cad Saude Publica, 2000; 16(3):671-679.

24. Mathers CD, Fat DM, Inoue M, Rao C, Lopez AD. Counting the dead and what they died from: an assessment of the global status of cause of death data. Bulll WHO 2005; 83(3):171-177.

25. Kanso S, Romero DE, Leite IC, Moraes EM. Diferenciais geográficos, socioeconômicos e demográficos da qualidade da informação da causa básica de morte dos idosos no Brasil. Cad Saude Publica, 2011; 27(7):1323-1339.

Artigo apresentado em 07/07/2012

Aprovado em 26/10/2012

Versão final apresentada em 13/11/2012 